\title{
Research on Risk Assessment and Control for Urban Rainwater Resources Utilization
}

\author{
Qin $\mathrm{Li}^{1, *}$, Ma Chengxiang ${ }^{1}$, Wang Junde ${ }^{1}$, Jin Yanzhao $^{2}$, Yang Guangdong ${ }^{3}$ \\ ${ }^{1}$ Gansu Academy for Water Conservancy, Lanzhou, Gansu, 730030, PR China \\ ${ }^{2}$ Gansu Research Institute for Conservation of Water and Soil, Lanzhou, Gansu, 730030, PR China \\ ${ }^{3}$ Qingyang Water Bureau, Qingyang, Gansu, 745200, PR China
}

\begin{abstract}
Strengthening risk management and control of urban rainwater resources utilization is the key to ensuring the sustainable and efficient use of urban rainwater resources. On the basis of comprehensive research on urban rainwater utilization, the definition and connotation of urban rainwater utilization emphasizing the attributes of resource utilization are proposed, and the definition and function model of urban rainwater utilization risk are established. Based on the whole process of the development and utilization of urban rainwater resources including external environment, urban natural and social characteristics, rainwater utilization engineering systems, and project operation management, the risk assessment index system for urban rainwater utilization and risk evaluation model by using Analytic Hierarchy Process are established, and a comprehensive risk assessment standard based on risk value and risk tolerance, as well as residual risk management and control theory and risk management methods are put forward. The results of research on risk assessment and control of rainwater resources utilization in Xifeng District of Qingyang City shows that the main risks of rainwater utilization in this district are as follows in order of severity: policies and regulations, economy developing level, maintenance costs, precipitation and natural eutrophication. Risk assessment shows that the risks are low and acceptable and thus can be reduced by strengthening daily monitoring and control.
\end{abstract}

\section{Introduction}

As a critical element in promoting water conservancy projects, establishing a risk management system for water resources has an important role to play in improving water resources management efficiency and effectiveness ${ }^{[1]}$. In the context of unconventional water resources being included in the unified allocation of water resources, risk management becomes more significant due to the unconventional nature of urban rainwater resources.

Rainwater is an unconventional water resource. Ideas associated with the utilization of rainwater keep springing up in the research and development of rainwater resources, including "rainwater utilization", "rainwater collection and utilization," "urban rainwater utilization," "urban rainwater collection and utilization" and "urban storm flood utilization," with each presenting certain findings on rainwater utilization at different stages. If we want to develop rainwater resources to increase water supply, the abovementioned ideas seem ill-defined and inadequate to explain the nature of urban rainwater resources. Therefore, it is necessary to redefine the idea of urban rainwater resource utilization. Lim et al. ${ }^{[2]}$ assessed the public health risks associated with viral pollutions in urban rainwater for household water supply in their study. The results showed that grain crop irrigation has the highest risk of viral infection, followed by showering and toilet flushing.
Sazakli et al. ${ }^{[3]}$ monitored and analyzed the quality of rainwater collected for household drinking water and its influence factors. The analysis showed that the microbiological parameters are mainly influenced by the cleanliness of the reservoir, while the chemical parameters were affected by the adjacent waters and human activities. Che et al. ${ }^{[4]}$ analyzed the water pollution of urban rainwater runoff and its influence factors. By researching the water quality of urban rainfall runoff, Hou et al. ${ }^{[5]}$ found that the water at road runoffs for loops and main lines is of the worst quality, below Class $\mathrm{V}$ in the Environmental Quality Standards for Surface Water of China; the rainwater runoff at the roof-tops and internal roads as well as natural rainwater runoffs all met the Class II quality standards. Cui et al. ${ }^{[6]}$ believed that potential health risks should be taken into consideration when recycling rainwater for grain crop irrigation, toilet flushing and river recharge. Jiang et al. ${ }^{[7]}$ analyzed factors influencing the water quality of urban rainwater runoffs. Cao et al. ${ }^{[8]}$ summarized the risks in rainwater utilization associated with operation, maintenance, design, construction, destruction and pollution. The abovementioned studies mainly focus on engineering risks and the effects of water quality risks on human health and agricultural irrigation, discussing risks in certain sections or aspects of urban rainwater resource utilization. However, rare research was conducted on the overall risks

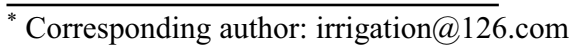


existing in the external environment and the whole process of rainwater resources utilization. Therefore, in order to improve the availability and utilization efficiency of unconventional rainwater resources, it is necessary to define and control the potential risks through the investigation into overall risk identification, assessment and control for rainwater resource utilization.

\section{Definition of urban Rainwater resource utilization and its risk}

\subsection{Definition and significance of urban rainwater resource utilization}

Unconventional water resource is a concept relative to conventional water resource. Unconventional water resources include seawater, brackish water, reclaimed water, rainwater, mine water, etc. ${ }^{[9]}$ Rainwater in city regions is called urban rainwater. By constructing projects that use rainwater without compromising the urban flood control and hydrologic ecological balance, urban rainwater resources can be utilized to increase the overall urban water resources and improve the efficiency in using water resources. The significance of urban resource utilization is as follows: (1) it clarifies the constraints on urban rainwater resource utilization, i.e., securing flood control and keeping the balance of hydrologic ecology.(2) it defines the access to urban rainwater resources, increasing the resource amount collected by rainwater harvesting and other engineering measures.(3) it points out the purpose of urban rainwater resource utilization, i.e., to increase available supply and integrate it into the unified configuration of urban water resources.

\subsection{Definition of urban rainwater resource utilization risk}

Risk is the impact of uncertainty on organizational objectives ${ }^{[10]}$. Generally, the overall risk in urban rainwater resources development and utilization is expressed by the following function model:

$$
R_{\mathrm{rwu}}=f\left(O_{\mathrm{wu}}, U_{\mathrm{wu}}, E_{\mathrm{wu}}\right)
$$

Where $R_{r w u}$ stands for urban rainwater resource utilization risk, $O_{w u}$ for urban rainwater resource utilization objective, $U_{w u}$ for the uncertainty in $O_{w u}$ generated throughout urban rainwater resource development and utilization, and $E_{w u}$ for the positive or negative impacts of $U_{w u}$ on $O_{w u}$.

Therefore, urban rainwater resource utilization risk means the positive or negative impacts of the uncertainty generated throughout the entire process on delivering goals in urban rainwater resource utilization.

\section{Risk management and control for urban rainwater resource utilization}

\subsection{Risk identification}

Urban rainwater resource utilization projects are projects built to support urban construction and the development of communities, roads, green spaces and squares, as well as rainwater development systems with low impact on the hydrographic net. They involve the construction of sponge roads, man-made lakes, stormwater detention tanks, ponds and artificial drainage systems. Generally speaking, urban rainwater resource utilization projects consist of rainwater collection system, pipe network system, water pretreatment system, impoundment system, purification system and utilization system. This study takes the external environment of urban rainwater resource development and utilization, the natural and social characteristics of urban areas, rainwater resource utilization project systems and the process of project operation and management as the basic environment for risk identification. Based on Eq. (1) and targeted at the possible risk sources that might influence rainwater resource development and utilization, an all-purpose, inclusive risk list of potential risks/risk events for urban rainwater resource utilization is established, followed by the using of the Delphi method to identify a risk assessment system for urban rainwater resource utilization composed of overall objective hierarchy $(\mathrm{O})$, objective hierarchy (A), rule hierarchy (B) and index hierarchy (C).

\subsection{Risk assessment}

Establishing a reasonable risk assessment system is necessary for the risk control of urban rainwater resource utilization. In order to assess utilization risk in a timesaving, effective manner, this study analyzes how risks at each hierarchy arise and spread, determines the influence of risk factors at each hierarchy and the index hierarchy on the urban rainwater resource utilization risk, and establishes the following risk assessment model according to function model of urban rainwater resources utilization risk and $\mathrm{AHP}^{[11]}$ (Analytic Hierarchy Process):

$$
R_{\mathrm{rwu}}=\sum R_{i} W_{i}
$$

Where, $R_{\text {rwu }}$ stands for urban rainwater resource utilization risk, $R_{i}$ for the risk value of index factor $C_{i}$. When the effects of $\mathrm{C}_{i}$ on urban rainwater resource utilization objectives are positive, $R_{i}$ is negative. Otherwise, it is positive. $W_{i}$ stands for the weight of the index factor $\mathrm{C}_{i}$ on the overall objective hierarchy $(\mathrm{O})$.

\subsubsection{Construction of judgment matrix}

In the established index system for urban rainwater resource utilization risk, all factors at the same hierarchy corresponding to a certain factor $\mathrm{A}_{i}$ should be marked as $\mathrm{B}_{1}, \mathrm{~B}_{2}, \ldots, \mathrm{B}_{\mathrm{n}}$. In order to compare their significance to $A_{i}$, the following matrix is constructed: 


$$
\mathrm{A}=\left(a_{i j}\right)_{n \times n}
$$

where, $\mathrm{a}_{i j}=\mathrm{B}_{i}: \mathrm{B}_{j}, \mathrm{a}_{i j}>0, \mathrm{a}_{i j}=1 / a_{i j}, \mathrm{a}_{i j}$ is the value standing for the relative importance of $\mathrm{B}_{i}$ to $\mathrm{B}_{j}$, based on their importance to $A_{i}$, judgment matrix $A$ decides how important $B_{1}, B_{2}, \ldots, B_{n}$ is to $A_{i}$.

\subsubsection{Scaling of judgment matrix factors}

The scaling of $\mathrm{a}_{i j}$ at the objective hierarchy (A) and rule hierarchy (B) in the judgment matrix is the same as the scaling used in AHP. The meaning of $\mathrm{B}_{i}: \mathrm{B}_{j}$ is shown in Table 1.

Table 1. Risk scale for target layer and criterion layer

\begin{tabular}{|c|c|}
\hline Grade & $\mathrm{B}_{i}: \mathrm{B}_{j}$ means \\
\hline 1 & Equally important \\
\hline 3 & More important \\
\hline 5 & Important \\
\hline 7 & Very important \\
\hline
\end{tabular}

Table 2. Levels \&evaluation standards of risk likelihood, severity and consequence for indicator layer

\begin{tabular}{|c|c|c|c|c|c|c|}
\hline \multirow{4}{*}{ Risk probability } & Grade & 1 & 2 & 3 & 4 & 5 \\
\cline { 2 - 7 } & Assessment criteria & Minimal & Narrow & Possible & Probable & Absolute \\
\hline \multirow{3}{*}{ Risk severity } & Grade & 1 & 2 & 3 & 4 & 5 \\
\cline { 2 - 7 } & Assessment criteria & Very slight & Slight & Moderate & Severe & Very severe \\
\hline \multirow{3}{*}{ Risk consequences } & Risk value & $0 \sim 5$ & $5 \sim 10$ & $10 \sim 15$ & $15 \sim 20$ & $20 \sim 25$ \\
\cline { 2 - 7 } & Assessment criteria & Low & $\begin{array}{c}\text { Relatively } \\
\text { low }\end{array}$ & Moderate & High & Very high \\
\hline
\end{tabular}

\subsubsection{Hierarchical single sort and judgment consistency test}

Targeted at a certain factor at the last hierarchy, single hierarchical sort is used to determine the weight of the importance order of the factors at the same hierarchy related to that factor. For the judgment matrix, first calculate is $\overline{\mathrm{W}}_{i}=\sqrt[n]{\prod_{j=1}^{n} a_{i j(i=1,2, \cdots, n)}}$. After vector normalization, $\quad \mathrm{W}_{i}=\bar{W}_{i} / \sum_{i=1}^{n} \bar{W}_{i}(i=1,2, \cdots, n) \quad$, where $\mathrm{W}_{i}$ is the single sort weight of the corresponding factor. Thus, $\mathrm{W}=\left[W_{1}, W_{2}, \cdots, W_{n}\right]^{T}$, standing for the single sort weight of the factors at a certain hierarchy on a certain factor at last hierarchy. To test the consistency of the judgment matrix, we should calculate its consistent index first through the equation $\mathrm{CI}=\lambda_{\max }-n / n-1$, where $\lambda_{\max }$ is calculated by $\lambda_{\max }=\sum_{i=1}^{n}(A W)_{i} / n W_{i}$. Meanwhile, $\mathrm{CI}$ is compared with the random consistency index $R I$. When $C I / R I<0.1$, the judgment matrix is consistent, and $\mathrm{W}$ is proved valid.

\begin{tabular}{|c|c|}
\hline 9 & Absolute importance \\
\hline $2,4,6,8$ & Median of the two adjacent judgmental items \\
\hline
\end{tabular}

For index hierarchy $(C)$ scaling, the first step is to determine the risk value $\mathrm{R}_{i}$ before replacing $\mathrm{B}_{i}: \mathrm{B}_{j}$ by $\mathrm{R}_{c i}: \mathrm{R}_{c j}$. The scaling meaning is the same as that at objective hierarchy and rule hierarchy. The corresponding risk consequences of each factor at index hierarchy are expressed as the product of corresponding risk probability and the severity of risk consequences. See Table 2 for risk probability, risk severity and risk consequences and assessment criteria.

$$
R_{i}=P_{i} \times S_{i}
$$

where, $\mathrm{R}_{i}$ stands for risk value, $\mathrm{P}_{i}$ for probability, and $S_{i}$ for severity.

Based on the requirements of risk analysis and relevant criteria and combined with relevant data, questionnaires are prepared for experts in the fields to grade and give feedback, followed by a comprehensively balanced analysis of the researcher, and finally the value of $a_{i j}$ in the judgement matrix can be determined. 
acceptable when the risk value is less than 10; risk with a value ranging within $10 \sim 15$ is defined as tolerable risks; if the risk is between 15 25, it is defined as intolerable risk. See Table 3 for the overall assessment.

Table. 3. Comprehensive risk assessment standards of urban rainwater resources utilization

\begin{tabular}{|c|c|c|c|c|c|}
\hline Risk tolerance & \multicolumn{2}{|c|}{ Acceptable risk } & Tolerable risk & \multicolumn{2}{c|}{ Intolerable risk } \\
\hline Risk value & $0 \sim 5$ & $5 \sim 10$ & $10 \sim 15$ & $15 \sim 20$ & $20 \sim 25$ \\
\hline Risk grade & Low & Relatively low & Moderate & High & Very high \\
\hline
\end{tabular}

\subsection{Risk management and control}

\subsubsection{Risk control theory}

The objectives of urban rainwater resource utilization risk control are to decrease or eliminate the negative impacts of the uncertainty on rainwater resource utilization and increase the availability of rainwater resources. Based on risk assessment, the following equation can be introduced to reduce the cost of risk control:

$$
R_{\mathrm{r}}=\mathrm{R}_{r w u}-\mathrm{R}_{a t}
$$

where, $R_{\mathrm{r}}$ stands for residual risk, $\mathrm{R}_{r w u}$ for urban rainwater resource utilization risk, and $\mathrm{R}_{a t}$ for acceptable or tolerable risks.

According to Equation (5), to control urban rainwater resource utilization is to control residual risk. In practice, the selection of $\mathrm{R}_{a t}$ value varies with the risk acceptance of the city. The upper limits are preferred. For cities short of water resources, $\mathrm{R}_{a t}$ value can be 15 , while for cities with abundant water resources, it can be 5 or 10 . When $R_{\mathrm{r}} \leq 0$, risk prevention such as constant monitoring and enhanced daily management is preferred. When $R_{\mathrm{r}}>$ 0 , comprehensive risk controls are in need to reduce risk incidence and risk-related losses.

\subsubsection{Risk control methods}

The influence of risk on the objectives can be either positive or negative. Therefore, risk control measures are varying accordingly. The main risk control measures are as follows: (1) Risk avoidance, i.e. to avoid or stop the negative risks that have significant impacts on urban rainwater resource utilization; (2) Risk amplification, i.e. to enhance the risk consequences or the incidence of an opportunity risk that has a positive effect; (3) Risk source elimination, i.e., to eliminate negative risks; (4) Change of the risk incidence or the impact of risk consequences; (5) Risk sharing, i.e., sharing the risk by switching the riskbearer without changing the size and nature of the risk itself; and (6) Risk retention, which can be applied to risks that were deemed acceptable or tolerable by risk assessment, as well as risks that cannot be dealt with at the current moment.

\section{Case study: water resources in Xifeng district, Qingyang city}

\subsection{Overview of water resources}

Qingyang City is in the east of Gansu Province, connecting Shaanxi, Gansu and Ningxia Province. Geographically speaking, it is located in the gully region of loess plateau in the middle and lower reaches of the Yellow River. The city is short of water due to a lack of resources, pollution and inadequate water conservancy facilities. Qingyang is a national energy-chemical industry base. However, water shortage in the area has become a major bottleneck on economic and social development. The average rainfall in Xifeng District is $561 \mathrm{~mm}$, and the average annual volume of water resources is $2.29 \times 10^{8} \mathrm{~m}^{3}$. The per capita water resources are $4.4 \times 10^{10} \mathrm{~m}^{3}$, accounting for $1 / 5$ of the national per capita water share. Low water level discourages the collecting of water resources from rivers. Rainfall in July to September accounts for $60 \%$ of the annual rainfall, with the precipitation forms being rainstorm and continuous rainfall. Thus, the runoff discharge results in water erosion at gully heads, which impairs ecological soundness and the integrality of tableland surface. In addition, rainwater runoffs carry a lot of sediment to the downstream areas, which causes soil erosion in the upper reaches and complicates the flood controls in the lower reaches ${ }^{[12]}$.

\subsection{Rainwater resource utilization}

In 2004, a man-made lake was completed in Xifeng District, Qingyang City, covering $1.22 \mathrm{~km}^{2}$, with a capacity of $1.388 \times 10^{5} \mathrm{~m}^{3}$. It was used for suburban irrigation, urban green space watering and street watering. The completion of the lack marked the beginning of urban rainwater resource utilization in Qingyang. In 2016, Qingyang was listed as one of the second batch pilot cities for sponge city development. Thus, the urban rainwater resource utilization system has basically taken shape.

Currently, there are four ways to utilize rainwater in Xifeng District. The first one is to build rainwatercollecting man-made lakes and rainwater reservoirs. The man-made lake system took the urban hardened ground, which covers $22.824 \mathrm{~km}^{2}$, as the collection areas. The collected rainwater resources formed five man-made lakes, namely Qingyang Lake, Bei Lake, Dongjiao Lake, Xi Lake and Dong Lake. Water source for irrigation from Bajiazui Reservoir was then transferred to drive the 
circulatory flow in the water system. The circulatory flow then connected the man-made lake system, forming an urban water system. The system is $23.907 \mathrm{~km}$ long, with an artificial river of $13.150 \mathrm{~km}$ surrounding the city. The total water area is $1.2504 \times 10^{6} \mathrm{~m}^{2}$, and the total capacity is $2.8720 \times 10^{6} \mathrm{~m}^{3}$. Among the five lakes, Qingyang Lake is the largest man-made lake in Xifeng's urban water system. It has a catchment area of $9.56 \mathrm{~km}^{2}$, a total water area of $3.322 \times 10^{5} \mathrm{~m}^{2}$, an average depth of around $3.88 \mathrm{~m}$, and a lake shoreline of $9.37 \mathrm{~km}$. Its total reservoir capacity and compound annual total water storage capacity are $1.2888 \times 10^{6} \mathrm{~m}^{3}$ and $2.8314 \times 10^{6} \mathrm{~m}^{3}$, respectively. Water from Qingyang Lake is mainly used for urban landscape and irrigation. The rainwater reservoir is located at Xifeng Industrial Park, used primarily as a back-up for industrial water used inside the park. Its rainfall collection capacity is $1.8 \times 10^{5} \mathrm{~m}^{3}$. The second one is to build rainwater resource utilization projects within administrative office lands and residential districts. Rainwater collection modules and storage facilities can be installed under permeable roads, ecological parking lots and sunken green space to store about $1.445 \times 10^{5} \mathrm{~m}^{3}$ water used for greenbelt watering and street cleaning. The third one is to store and utilize road rainwater. The rainwater reservoirs are built to support urban road construction, storing about $5900 \mathrm{~m}^{3}$ water mainly used for greenbelt watering. The final one is to store and utilize rainwater from squares and green spaces. Filtered rainwater collected from large squares and urban green spaces accounts for about 2.623 $\mathrm{x} 10^{5} \mathrm{~m}^{3}$ water for greenbelt watering and square cleaning.

\subsection{Risk identification and assessment system}

Throughout the development and utilization of urban rainwater resources, the risks, on the one hand, have arisen from the uncertainty in the external environment of development and utilization, such as laws, regulations and policies, macroeconomic conditions, and public opinions. Risks related to such factors are called development and utilization environment risk. On the other hand, they have arisen from the uncertainty in developing and utilizing rainwater resources, such as resource endowment, pollution and water price. Such risks are categorized by nature as water volume risk, water quality risk and water price risk. Therefore, urban rainwater resource utilization risk includes development and utilization environment risk, water volume risk, water quality risk and water price risk. According to risk identification method and based on the water utilization conditions in Qingyang, a preliminary risk list was prepared. Experts were invited to participate in interviews and fill in questionnaires. After data analysis, an urban rainwater resource utilization risk assessment system was established according to the overall objective hierarchy (O), objective hierarchy (A), rule hierarchy (B) and index hierarchy (C) (Figure 1). The objective hierarchy consists of development and utilization environment risk $\left(A_{1}\right)$, water volume risk $\left(A_{2}\right)$, water quality risk $\left(\mathrm{A}_{3}\right)$ and water price risk $\left(\mathrm{A}_{4}\right)$, the rule hierarchy consists of 7 indicators, including social environment $\left(B_{1}\right)$, ecological environment $\left(B_{2}\right)$, resource endowment $\left(\mathrm{B}_{3}\right)$, construction and operation management
$\left(\mathrm{B}_{4}\right)$, pollution sources $\left(\mathrm{B}_{5}\right)$, water treatment $\left(\mathrm{B}_{6}\right)$ and water price $\left(\mathrm{B}_{7}\right)$, and the index hierarchy consists of 22 indicators, including policies and regulations $\left(\mathrm{C}_{1}\right)$, economic development $\left(\mathrm{C}_{2}\right)$, public opinion $\left(\mathrm{C}_{3}\right)$, regional environment $\left(\mathrm{C}_{4}\right)$, urban water system $\left(\mathrm{C}_{5}\right)$, flood $\left(\mathrm{C}_{6}\right)$, soil erosion $\left(C_{7}\right)$, rainfall $\left(C_{8}\right)$, groundwater $\left(C_{9}\right)$, surface water $\left(\mathrm{C}_{10}\right)$, catchment area $\left(\mathrm{C}_{11}\right)$, storage capacity $\left(\mathrm{C}_{12}\right)$, engineering design standards $\left(\mathrm{C}_{13}\right)$, engineering construction $\left(\mathrm{C}_{14}\right)$, operation management $\left(\mathrm{C}_{15}\right)$, physical pollution $\left(\mathrm{C}_{16}\right)$, chemical pollution $\left(\mathrm{C}_{17}\right)$, natural eutrophication $\left(\mathrm{C}_{18}\right)$, purification process $\left(\mathrm{C}_{19}\right)$, purification facilities $\left(\mathrm{C}_{20}\right)$, maintenance costs $\left(\mathrm{C}_{21}\right)$ and treatment costs $\left(\mathrm{C}_{22}\right)$.

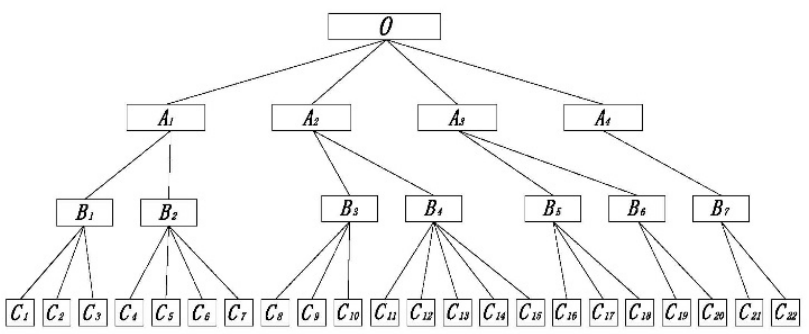

Fig.1. Risk assessment Index structure of urban rainwater utilization

\subsection{Assessment of rainwater resource utilization}

Following a deep investigation into the rainwater resource utilization in Xifeng District and close consultation with experts and administrators in the related field, the authors scored the risk factors at each hierarchy of the risk assessment system and conducted an empirical study.

\subsubsection{Index weight calculation}

Based on the hierarchical structure of the risk assessment system, 12 judgment matrices were established for single hierarchical sort, hierarchical overall sort and consistency test from top to bottom.

(1) The relative weights of $A_{1}, A_{2}, \cdots, A_{4}$ at the objective hierarchy on the overall hierarchy $(\mathrm{O})$ were calculated. $\mathrm{O} \rightarrow \mathrm{A}$ judgment matrix and the results of hierarchical sort are shown in Table 4.

Table 4. $\mathbf{O} \rightarrow$ A Judgment matrix and hierarchical arrangement of target layer

\begin{tabular}{|c|c|c|c|c|c|c|}
\hline 0 & $\mathrm{~A}_{1}$ & $\mathrm{~A}_{2}$ & $\mathrm{~A}_{3}$ & $\mathrm{~A}_{4}$ & $\mathrm{~W}_{\mathrm{A}}$ & Ranking \\
\hline $\mathrm{A}_{1}$ & 1 & 2 & 3 & 2 & 0.43 & 1 \\
\hline $\mathrm{A}_{2}$ & 0.5 & 1 & 1 & 2 & 0.23 & 2 \\
\hline $\mathrm{A}_{3}$ & 0.33 & 1 & 1 & 2 & 0.21 & 3 \\
\hline $\mathrm{A}_{4}$ & 0.5 & 0.5 & 0.5 & 1 & 0.14 & 4 \\
\hline$\lambda_{\text {max }}=4.082, \mathrm{CI}=0.027, \mathrm{RI}=0.9, \mathrm{CR}=0.03<0.1$ \\
\hline
\end{tabular}

(2) The relative weights of $B_{1}, B_{2}, \cdots, B_{7}$ at the rule hierarchy on $A_{1}, A_{2}, \cdots, A_{4}$ at the objective hierarchy was calculated. Then the weight of $A_{1}, A_{2}, \cdots, A_{4}$ was used to 
weight the corresponding weight of the rule hierarchy, and then the combined weight of each factor at the rule hierarchy was calculated. The $\mathrm{A}_{i} \rightarrow \mathrm{B}$ judgment matrix and single hierarchical sort were similar to that of $\mathrm{O} \rightarrow \mathrm{A}$. See Table 5 for the overall hierarchical sort for the rule hierarchy.

(3) The relative weights of $\mathrm{C}_{1}, \mathrm{C}_{2}, \cdots, \mathrm{C}_{22}$ at the index hierarchy on $\mathrm{B}_{1}, \mathrm{~B}_{2}, \cdots, \mathrm{B}_{7}$ at the rule hierarchy were calculated. The $\mathrm{B}_{4} \rightarrow \mathrm{C}$ judgment matrix and single hierarchical sort are shown in Table 6 . The weight of each factor at index hierarchy $\mathrm{W}_{i}$ and the results from sort are shown in Table 7, and calculation was the same as that of the hierarchical overall sort at the rule hierarchy.

Table 5. Hierarchical total arrangement of criterion layer

\begin{tabular}{|c|c|c|c|c|c|c|}
\hline$A_{i}$ & $\mathrm{~A}_{1}$ & $\mathrm{~A}_{2}$ & $\mathrm{~A}_{3}$ & $\mathrm{~A}_{4}$ & \multirow{2}{*}{$\mathrm{W}_{\mathrm{B}}$} & \multirow{2}{*}{ Ranking } \\
\hline $\mathrm{W}_{a}$ & 0.43 & 0.23 & 0.21 & 0.14 & & \\
\hline $\mathrm{B}_{1}$ & 0.67 & & & & 0.28 & 1 \\
\hline $\mathrm{B}_{2}$ & 0.33 & & & & 0.14 & 3 \\
\hline $\mathrm{B}_{3}$ & & 075 & & & 0.17 & 2 \\
\hline $\mathrm{B}_{4}$ & & 0.25 & & & 0.06 & 6 \\
\hline $\mathrm{B}_{5}$ & & & 0.67 & & 0.14 & 4 \\
\hline $\mathrm{B}_{6}$ & & & 0.33 & & 0.07 & 5 \\
\hline $\mathrm{B}_{7}$ & & & & 1 & 0.14 & 7 \\
\hline
\end{tabular}

Table.6. $\mathrm{B}_{4} \rightarrow \mathrm{C}$ Judgment matrix and hierarchical single arrangement

\begin{tabular}{|c|c|c|c|c|c|c|}
\hline $\mathrm{B}_{4}$ & $\mathrm{C}_{11}$ & $\mathrm{C}_{12}$ & $\mathrm{C}_{13}$ & $\mathrm{C}_{14}$ & $\mathrm{C}_{15}$ & $\mathrm{~W}_{\mathrm{i}}$ \\
\hline $\mathrm{C}_{11}$ & 1 & 1.07 & 2 & 1.6 & 1.33 & 0.26 \\
\hline $\mathrm{C}_{12}$ & 0.94 & 1 & 1.86 & 1.5 & 1.25 & 0.25 \\
\hline $\mathrm{C}_{13}$ & 0.5 & 0.53 & 1 & 0.8 & 0.67 & 0.13 \\
\hline
\end{tabular}

\begin{tabular}{|l|c|c|c|c|c|c|}
\hline $\mathrm{C}_{14}$ & 0.63 & 0.67 & 1.25 & 1 & 0.83 & 0.16 \\
\hline $\mathrm{C}_{15}$ & 0.75 & 0.8 & 1.5 & 1.2 & 1 & 0.2 \\
\hline$\lambda_{\max }=5.0, \quad \mathrm{CI}=0.0, \quad \mathrm{RI}=0.12, \quad \mathrm{CR}=0.0<0.1$ \\
\hline
\end{tabular}

\subsubsection{Index factor risk and urban rainwater resource utilization risk calculation}

The risk value of each risk factor is determined based on the calculation of the weight of each risk factor at the index hierarchy, as well as the expert-assessed risk probability and severity of risk consequences at the index hierarchy, with the positive and negative effects of risk taken into consideration. For the factors at the index hierarchy, policies and laws, flood and soil erosion have positive impacts on urban rainwater resource utilization, while the rest of the factors have negative impacts. Firstly, the national and local policies and laws on urban rainwater resource utilization (e.g. Guiding Opinions of the General Office of the State Council on Promoting the Construction of Sponge City, Project Plan for Urban Rainwater Engineering in Xifeng District of Qingyang City) and the selection of Qingyang as a pilot city for sponge city development have encouraged the utilization of urban rainwater resource in Qingyang. Secondly, among all cities in Gansu Province, Qingyang has the richest accumulated rainstorm in the past 60 years, making itself one of the areas most exposed to rainstorm and flood risk. In order to address the problem of urban soil erosion once and for all, the local government made full use of the natural rain and flood resources ${ }^{[13]}$. Thus, flood and soil erosion indirectly facilitate the urban rainwater resource utilization, exerting a positive impact. The risk values for the factors at index hierarchy are shown in Table 8 . According to the calculation using the risk assessment model, the risk value of the current rainwater resource utilization in Xifeng District, Qingyang City is 8.98.

Table 7. Hierarchical total ordering of indicator layer

\begin{tabular}{|c|c|c|c|c|c|c|c|c|c|c|c|}
\hline $\mathrm{C}_{i}$ & $\mathrm{C}_{1}$ & $\mathrm{C}_{2}$ & $\mathrm{C}_{3}$ & $\mathrm{C}_{4}$ & $\mathrm{C}_{5}$ & $\mathrm{C}_{6}$ & $\mathrm{C}_{7}$ & $\mathrm{C}_{8}$ & $\mathrm{C}_{9}$ & $\mathrm{C}_{10}$ & $\mathrm{C}_{11}$ \\
\hline $\mathrm{W}_{i}$ & 0.1337 & 0.1002 & 0.0501 & 0.0252 & 0.0189 & 0.0505 & 0.0473 & 0.0706 & 0.0424 & 0.0565 & 0.0148 \\
\hline Ranking & 1 & 2 & 10 & 16 & 17 & 9 & 11 & 4 & 13 & 8 & 18 \\
\hline $\mathrm{C}_{i}$ & $\mathrm{C}_{12}$ & $\mathrm{C}_{13}$ & $\mathrm{C}_{14}$ & $\mathrm{C}_{15}$ & $\mathrm{C}_{16}$ & $\mathrm{C}_{17}$ & $\mathrm{C}_{18}$ & $\mathrm{C}_{19}$ & $\mathrm{C}_{20}$ & $\mathrm{C}_{21}$ & $\mathrm{C}_{22}$ \\
\hline $\mathrm{W}_{i}$ & 0.0139 & 0.0074 & 0.0093 & 0.0111 & 0.0514 & 0.0257 & 0.0616 & 0.0443 & 0.0333 & 0.0799 & 0.0599 \\
\hline Ranking & 19 & 22 & 21 & 20 & 7 & 15 & 5 & 12 & 14 & 3 & 6 \\
\hline
\end{tabular}

Table 8. Factor risk value of indicator layer

\begin{tabular}{|c|c|c|c|c|c|c|c|c|c|c|c|}
\hline $\mathrm{C}_{i}$ & $\mathrm{C}_{1}$ & $\mathrm{C}_{2}$ & $\mathrm{C}_{3}$ & $\mathrm{C}_{4}$ & $\mathrm{C}_{5}$ & $\mathrm{C}_{6}$ & $\mathrm{C}_{7}$ & $\mathrm{C}_{8}$ & $\mathrm{C}_{9}$ & $\mathrm{C}_{10}$ & $\mathrm{C}_{11}$ \\
\hline $\mathrm{R}_{i}$ & -16 & 12 & 6 & 8 & 6 & -16 & -15 & 20 & 12 & 16 & 16 \\
\hline $\mathrm{C}_{i}$ & $\mathrm{C}_{12}$ & $\mathrm{C}_{13}$ & $\mathrm{C}_{14}$ & $\mathrm{C}_{15}$ & $\mathrm{C}_{16}$ & $\mathrm{C}_{17}$ & $\mathrm{C}_{18}$ & $\mathrm{C}_{19}$ & $\mathrm{C}_{20}$ & $\mathrm{C}_{21}$ & $\mathrm{C}_{22}$ \\
\hline $\mathrm{R}_{i}$ & 15 & 8 & 10 & 12 & 10 & 5 & 12 & 8 & 6 & 12 & 9 \\
\hline
\end{tabular}




\subsubsection{Risk assessment and control}

According to the risk assessment criteria and results, the rainwater resource utilization risk in Xifeng District, Qingyang City is relatively low and acceptable.

Based on the urban rainwater resource utilization risk control theory and the water resources conditions in Qingyang, when $\mathrm{R}_{a t}$ is valued at 15 or $10, R_{\mathrm{r}}<0$. Therefore, risk prevention should be the main risk control measure for Qingyang. Risk retention should be adopted based on risk control methods and AHP results, combined with enhanced constant monitoring and management. The main control measures are listed as follows:

(1) Maintain the stability and consistency of laws and regulations on rainwater resource development and utilization to a certain extent and ensure the continuity of incentive mechanism such as preferential policies.

(2) Develop the urban economy to increase investment in rainwater resource utilization steadily.

(3) Compile project maintenance cost control plan and adopt comprehensive measures to reduce maintenance costs.

(4) Reasonably determine the design rainfall of rainwater resource utilization project, predict the type and area of the rainwater collecting surface and other factors that may change in the future; prepare a reasonable plan for the projects to ensure there is enough urban rainwater.

(5) Adopt engineering and technical measures to reduce the risks in the water storage system, such as the eutrophication of man-made lakes.

(6) Monitor and manage the physical and chemical pollution occurring below the surface of the city.

\section{Conclusion}

Case study of the urban rainwater resource utilization risk assessment and control in Xifeng District, Qingyang City shows that the risk identification method, the overall risk assessment system, assessment model and criteria, and control theories and methods proposed in this paper can effectively identify and study the major risks during unconventional rainwater resource development and utilization, and clarify risk grade and determine control measures to reduce or eliminate the risks, increasing the available urban rainwater resource and improving the efficiency of rainwater resource utilization. Also, it provides a rainwater resource utilization risk control model for future research in a different city.

\section{Acknowledgments}

This research work is funded by project of Study on Development and Utilization Potential of Rain Flood Resources and Risk Control of its Whole Process (2017YFC0403504) and the International Science \& Technology Cooperation Program of Gansu province (18YF1WA030)

\section{References}

1. Wang, H., Wang, J. (2012) Sustainable Utilization of China's Water Resources. Bulletin of Chinese Academy of Sciences, 27:352-358.

2. Lim, K.Y., Hamilton, A.J., Jiang, S.C. (2015) Assessment of Public Health Risk Associated with Viral Contamination in Harvested Urban Stormwater for Domestic Applications. Science of the Total Environment, 523:95-108.

3. Sazakli, E., Alexopoulos, A., Leotsinidis, M. (2007) Rainwater harvesting, quality assessment and utilization in Kefalonia Island, Greece. Water Research, 41:2039-2047.

4. Che, W., Li, J., Cao, X., et al (2001) Analysis on Urban Runoff Recharge to Groundwater. Urban environment \& urban ecology, 14:28-30.

5. Hou, P., Ren, Y., Wang, X., et al (2012) Research on Evaluation of Water Quality of Beijing Urban Stormwater Runoff. Environmental Science, 33:71-73.

6. Cui, B., Gao, F., Li, Z., et al (2019) The Use of Brackish and Reclaimed Waste Water in Agriculture: A Review. Journal of Irrigation and Drainage, 38:6068.

7. Jiang, D., Jiang, W. (2008) A Study of Water Quality of Rainfall Runoff in Cities of China and Abroad.Geophysical \& Geochemical Exploration, 32:417-420.

8. Cao, W., Jia, A., Li, X. (2008) Risk Evaluation on the Collection and Reuse of Stormwater in Residential Districts. Water \& Wastewater Engineering, 34:71-74.

9. Gao, C., Liu, X. (2007) Application Research Progress of Urban Unconventional Water Resources. Journal of Irrigation and Drainage, 26:68-70.

10. ISO, AS/NZS. (2009) AS/NZS ISO 31000:2009 Risk management - principles and guidelines. Published in Switzerland, Bern.

11. Saaty, T.L. (1988) What is the Analytic Hierarchy Process? Springer, Berlin.

12. Jia, X., Fan, Z., Li, L. (2011) Practice on Collection and Utilization of Rain Flood Runoff in Qingyang City. Soil and Water Conservation in China, 1:pp.2930.

13. Pei, H., Chen, J., Li, X., et al. (2017) Spatiotemporal Pattern and Risk Assessment of Storm Flood in Gansu Province. Journal of Natural Disasters, 26:165-175. 